\title{
Pattern Recognition: A True Clinician's Pearl in Rheumatology
}

MUHAMMAD HAROON, MB, MMedSc, MRCPI; SINEAD HARNEY, MB, FRCPI, DPhil (Oxon); JOHN G. RYAN, MB, MRCPI, Department of Rheumatology, Cork University Hospital, Cork, Ireland. Address correspondence to Dr. M. Haroon; E-mail: mharoon301@ hotmail.com. J Rheumatol 2011;38:1130-1; doi:10.3899/jrheum.101138

We describe a case in which pattern recognition of a rheumatologic condition disclosed an underlying malignant process. To our knowledge this is the first reported case of unilateral palmar fasciitis and polyarthritis syndrome, which has traditionally been described as bilateral inflammatory arthritis and fasciitis $1,2,3,4$.

The patient, a 70-year-old woman, had a 5-week history of gradually worsening flexion contractures of the left hand along with a 3-week history of left hand pain and swelling. There were no symptoms to suggest an underlying connective tissue disease or a generalized arthropathy. Clinical examination revealed thickened fascia of left palm with flexion contractures of all fingers of the left hand (Figure 1). Synovitis of the wrist, metacarpophalangeal, and proximal interphalangeal joints was notable (Figure 2). The left palm showed palmar, induration, and digital contracture (Figure $3)$. Her hand radiographs were unremarkable. The clinical syndrome of palmar fasciitis and polyarthritis syndrome was suspected. The patient was an active smoker, and as this condition is frequently associated with an underlying malignancy, we performed a computed tomography scan of the

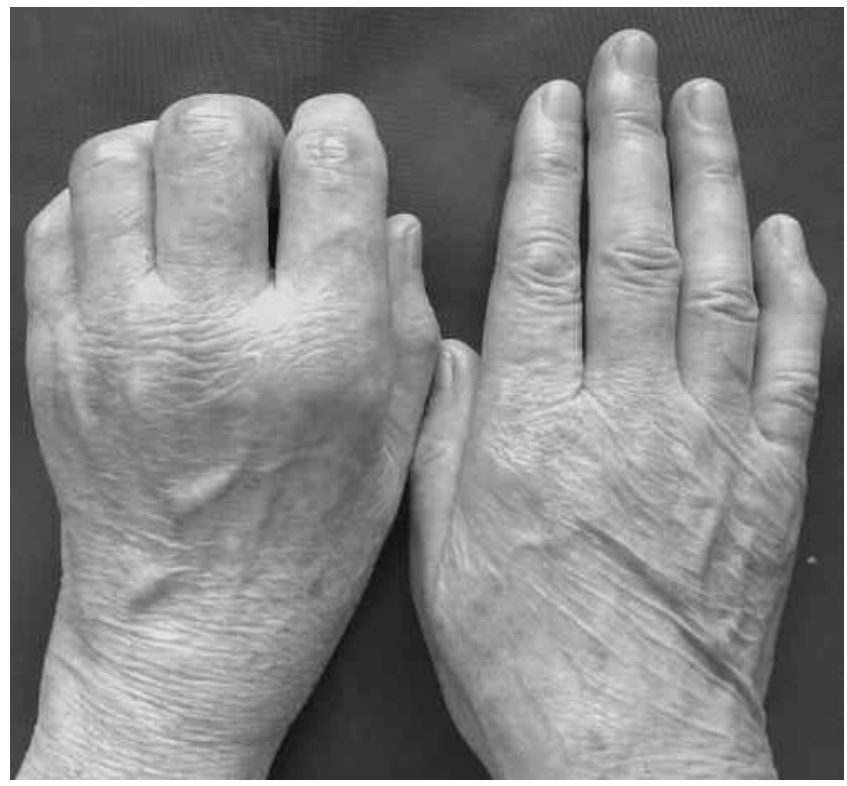

Figure 1. Dorsal view of both hands. Unilateral appearance of significant left-hand digital contracture is evident. thorax. The scan demonstrated an occult bronchogenic carcinoma - a $3.1 \times 3.3 \mathrm{~cm}$ mass in the anterior segment of the left upper lobe, with enlarged precarinal, aortopulmonary,

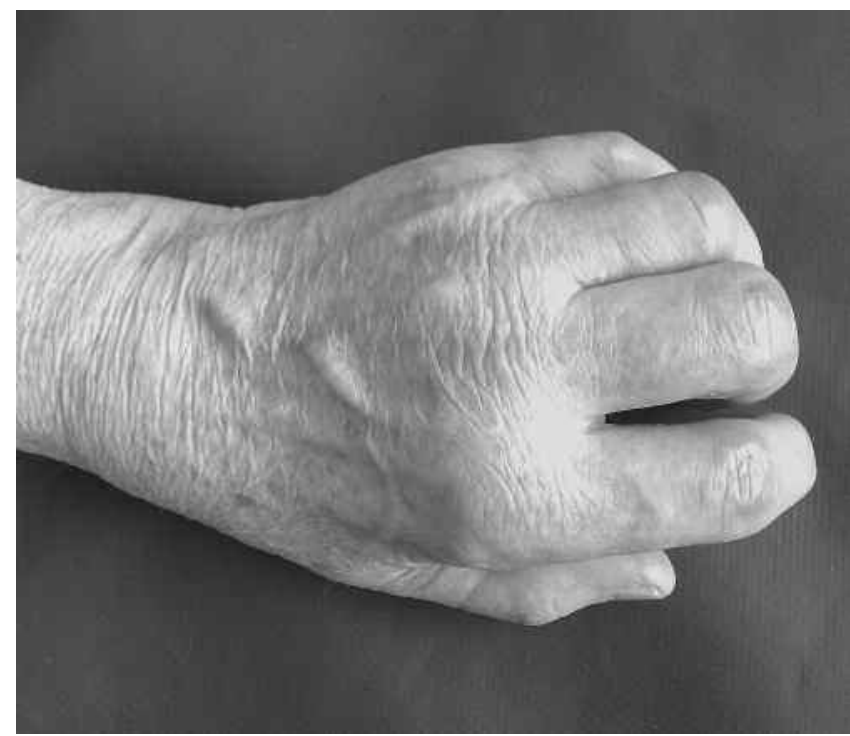

Figure 2. Dorsal view of left hand reveals synovitis of proximal interphalangeal and metacarpophalangeal joints. Moreover, synovitis of the left wrist is apparent.

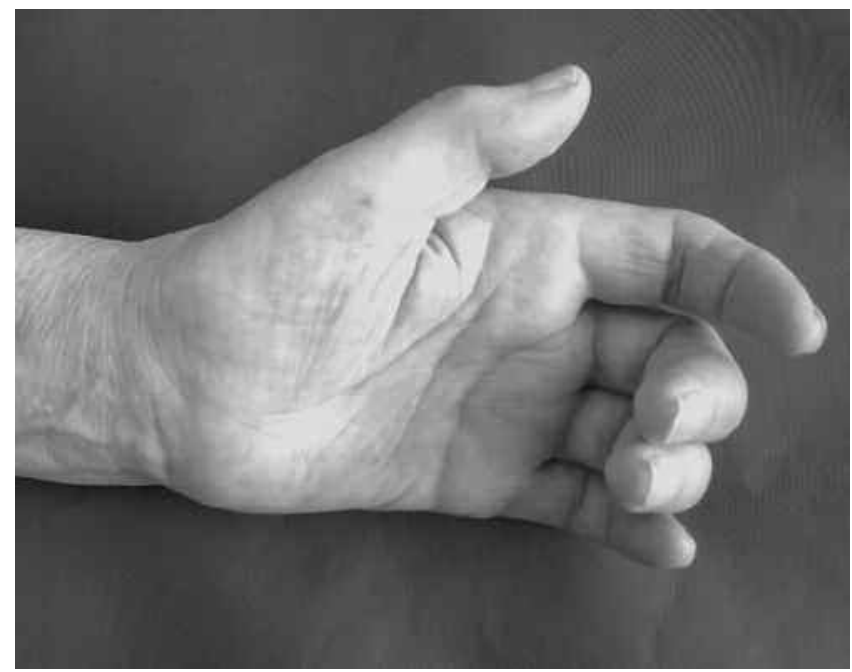

Figure 3. Left palmar view shows palmar thickening, induration, and digital contractures.

Personal non-commercial use only. The Journal of Rheumatology Copyright ( 2011. All rights reserved. 
and subcarinal lymph nodes. Subsequent lymph node biopsy confirmed metastatic non-small cell lung carcinoma. There was no clinical and radiological (magnetic resonance imaging) evidence of brachial plexus involvement.

The patient has since received palliative chemotherapy; however, her joint and palmar fascia changes persist. Pattern recognition is important in classifying rheumatologic diseases, and atypical presentations should prompt a thorough evaluation to exclude sinister pathology.

\section{REFERENCES}

1. Marie I, Cailleux N, Roca F, Benhamou Y, Scotte M, Levesque H. Palmar fasciitis and polyarthritis syndrome. QJM 2010;103:703-4.

2. Sheehy C, Ryan JG, Kelly M, Barry M. Palmar fasciitis and polyarthritis syndrome associated with non-small-cell lung carcinoma. Clin Rheumatol 2007;26:1951-3 .

3. Yogarajah M, Soh J, Lord B, Goddard N, Stratton R. Palmar fasciitis and polyarthritis syndrome: a sign of ovarian malignancy. J R Soc Med 2008;101:473-5.

4. Haroon M, Phelan M. A paraneoplastic case of palmar fasciitis and polyarthritis syndrome. Nat Clin Pract Rheumatol 2008;4:274-7. 